\title{
Public Documents Instruction in Library Schools
}

$\mathrm{Mr}$. Lilley is an associate, School of $\mathrm{Li}^{-}$ brary Service, Columbia University.

Tow Much, and what kind of instruc$\Gamma$ tion in public documents are the students getting in today's library schools? This is a question that seems to be asked with some frequency whenever librarians get together. In part, no doubt, it reflects an awareness of the increasingly important role the various agencies of government are playing in the daily lives of every individual, and a recognition on the part of librarians of the importance of public documents for many purposes in libraries of all kinds. In part it grows out of a realization of the complexity of government publications and an understanding of the need for special knowledge about documents on the part of those who handle them in libraries. But still another factor, likely to be responsible in some degree for the frequency with which the question is asked these days, has to do with the library schools themselves. How have the curriculum changes with which many of the schools have been experimenting for the past few years affected the teaching of documents? What has happened in those schools that once offered courses in government publications and that now make no mention of the subject in their catalogs of course offerings? In I934 when the ALA Public Documents Committee sponsored an earlier study concerned with the teaching of public documents in library schools it was found that two patterns of instruction were in exist- ence: in the one the major attention to government publications was provided in separate courses; in the other various aspects of documents topics were distributed through the curriculum in reference, bibliography, cataloging, and other courses. To what extent are each of these patterns being followed today? Are there major differences in the amount or kind of instruction provided under the two plans?

It is a healthy sign of professional interest in the training of our oncoming librarians that we should find these questions being posed, and it was for the purpose of trying to find some answers to such questions that the Public Documents Committee asked the writer to make a report to it on this subject during the ALA Conference in New York in 1952. The present article is an adaptation of the paper read before the Committee on that occasion.

Because adequate answers could not be found in any printed sources it became necessary to prepare a questionnaire. In this an attempt was made to discover the pertinent facts not only about the documents courses as such, but also about every course offered, in a sampling of library schools, in which one hour or more was normally devoted to some aspect of government publications. Copies of this questionnaire were sent out in May, I952, and most of the returns were in by early June.

For the sampling of schools to which the questionnaire was to be sent, the list of library schools approved by the Board of Education for Librarianship was selected 
in spite of its known limitations. The chief of these, as will be found explained on page I 54 of the ALA Bulletin for May, 1952, is that no names have been added to, or removed from, this list since August, I 948, and it therefore fails to include any of the good new schools that have developed since that date. But despite its omissions this seemed to be the only practicable list available for sampling purposes, and it did have the merit of distinguishing between schools operating at three different levels of library education. Thus it included five schools known as Type I which meant that they required a college degree for admission and/or that they gave advanced professional training beyond the first year of library science. It named i 8 Type II schools which required four years of appropriate college work for admission but gave only the first full academic year of library science, and finally it included I4 Type III schools which gave only the first year of library science and included the curriculum within the four undergraduate college years. One school was accredited for both a Type II and a Type III curriculum, and another school had voluntarily given up its accredited standing before this study was begun, so that there was a total of 35 schools to which the questionnaire could be sent. Replies either in whole or in substantial part were received from 30 of these 35 schools so that the figures used in this report are based on an $85.71 \%$ return from the sampling.

By means of letters, or from information available in the catalog descriptions of courses, it was possible to get information about an even higher percentage of the schools on some points. For example, it could be determined that every one of the 35 schools gives some attention to government publications. Naturally the amount and kind of attention varies from school to school. But the rumor heard every now and then that "many library schools today don't teach government documents at all" would appear to be just not so. Another piece of information that could be discovered for every one of the 35 schools was whether or not a separate documents course is offered. The answer is that 19 schools $(54.28 \%)$ do have documents courses, 16 schools $(45.7 \mathrm{I} \%)$ do not. The division therefore is not quite half and half. Breaking this result down according to the three types of schools it was found that documents courses are offered by 4 of the 5 , or $80 \%$ of the Type I schools; by 12 of the I 8 , or $663 \%$ of the Type II schools; and by 3 of the 12 , or $25 \%$ of the Type III schools.

In order to find out what subjects are most commonly covered in the special documents courses, and which ones receive emphasis, the questionnaire provided a list of I 2 suggested topics (with space for others to be inserted), asking the schools to report the number of hours spent on each topic in each course. For the 18 documents courses for which this information was supplied, 7 of the 12 topics are included in at least I7 courses: "Subject content of government publications," "Reference work with government publications," "Bibliographies and indexes of government documents," Legislative procedures and laws," "Methods and problems of acquisition," "Organization of government documents in collections," and "History of the printing and distribution of government publications." These 7 topics account for nearly $70 \%(69.6 \%)$ of the total class time of the documents courses. Fifteen of the 18 documents courses also spend time on "Organization of governmental issuing agencies," and I4 of the courses consider both "Selection tools for use with government publications," and "Activities and publishing policies of the various issuing agencies." Twelve courses 
provide "Special consideration of the almost infinite variety of types of publications issued by governmental agencies." But only 8 of the 18 schools include some instruction about the cataloging of government publications in their documents courses.

To get a better picture of the complete instruction in government publications offered in these 18 schools, we must add to the topics covered in the special documents courses such additional instruction as is provided in other courses in these same schools, for no school reported that it gave all of its instruction about government publications in its documents course. Examining the returns to discover the topics on which time is spent in outside courses in those schools that offer a basic documents course, we find "Reference work with documents," "Bibliographies and indexes of documents," "Cataloging of government publications," and "Subject content of government publications" heading the list, and representing $68.17 \%$ of the total time spent on government documents in the outside courses. Thus reference, bibliography, and subject content of documents commonly represent important aspects of government publications both in the documents courses and in other courses in the same schools. Cataloging of documents, as might be expected, is usually studied only in the nondocuments courses.

Turning now to the schools that do not have special documents courses, we find exactly the same four subjects heading the list: "reference work with government publications," "cataloging," "subject content," and "bibliographies and indexes of documents." The major emphases on subject matter are therefore the same in both kinds of schools. Making a closer comparison, topic by topic, there is found to be some variation in every subject as to the propor- tion of total time it receives under the two kinds of programs. But the surprising thing is that the greatest variation shown for any subject is only $6.3 \%$, while the average for all variations is only $2.58 \%$. It seems fair to say, therefore, that not only are the same subjects covered under both teaching programs, but the difference in emphasis on individual subjects is relatively insignificant.

It might be interesting at this point to take a look at the kinds of courses in which these topics are covered in those schools that spread their documents instruction through the curriculum. According to the reports received, these schools provide on the average about $56.5 \%$ of their total coverage for government publications in the Reference courses, $19 \%$ in Cataloging and Classification, $6 \%$ in Bibliography courses, about $5 \%$ in Administration, between $3 \%$ and $4 \%$ each in,courses devoted to Book Selection or to the various subject fields: Social Science, Science, or Humanities Literature, and only about $3 \%$ in miscellaneous courses. Over $80 \%$ of the total instruction in government publications therefore, takes place in the Reference, Bibliography, and Cataloging courses.

So far we have been considering only the proportions of total time spent on various topics under the two kinds of teaching programs, and have not yet examined the actual amounts of time spent on documents instruction. From the information reported by the 30 schools, the tabulations favor those schools with documents courses when it comes to considering the total number of class hours of document offerings. For those schools with documents courses, supplemented by some document instruction in other courses, the average amount of time provided for public documents is 50.77 class hours per school. This is to be compared with an average of only 34.37 class hours 
spent on documents in those schools that do not offer a separate documents course. This difference of 16.4 class hours is equivalent, depending on variations in course lengths and number of class meetings per week in different schools, to something like a third or a half of an entire semester's work in one course. Schools without documents courses therefore, offer on the average only a little over $3 / 5$ as much time with government publications as do schools that have documents courses.

But of course there is another way of looking at this situation. Those who favor the integration of documents topics with related subjects through the curriculum may point out here that what really matters is not how many hours of instruction a school offers, but how many hours of instruction the average student receives. In this connection the questionnaire results show, first of all, that most of the special documents courses are elective. Only one school reported that its documents course is required. One other school reported that students must take either the documents course or one in the Bibliography of Sciences. All the other 16 schools that reported on this point stated that their documents courses are elective. Just what this means seems to vary with the school. One school, after stating that its course is elective added: "But most students usually seem to take it." Another school commented: "The requirement of 30 hours in Library Science leaves no opportunity for the extra elective in Government Documents except in the case of an honors course for a previous graduate coming back for additional work." It is probable that neither of these extremes is typical. But it is equally reasonable to suppose that every school having an elective documents course graduates a number of students each year who did not enrol for this course. How much documents education do these students get? The answer seems to be that they get less than students who have taken the required courses in a school that has no documents course. This is a perfectly understandable situation. If one school puts the bulk of its documents training in one elective course, and another school spreads all of its training in documents through courses like Reference, Bibliography and Cataloging, which usually are required, the former school may provide more opportunity for instruction, but the latter actually demands more of each student. The results of the study show appreciable differences here. The average required class time on public documents in schools with elective documents courses is 15.3 hours (the range is from I hour to 44 ). The average required class time on government publications in schools without a documents course is 26.79 hours (the range is from 3 hours to 70). Thus, taken as a group, the latter schools require every student to have $\mathrm{I} \frac{3}{4}$ times as many class hours in documents as do the former schools.

In a kind of rough summary of this part of the findings, it can be shown that a student who is interested in documents, who attends a school that offers a course in documents, and who takes the course, can receive considerably more instruction about government publications than can a similarly interested student who attends a school where there is no documents course for him to take. On the other hand, a student who takes only the required courses in either kind of school receives more than half again as much instruction in documents if he goes to a school that has no documents course. Which is the more meaningful way of interpreting this situation? That, undoubtedly, is a question that will continue to be debated by librarians and by library school teachers just as enthusiastically in the 
future as it has been debated in the past!

Turning now to see what kinds of documents are being studied in the various schools, and leaving out the Canadian schools for the moment, the tabulations show that all the other I 7 documents courses about which information on this point was supplied spend from 50\% to $96 \%$ of their time on U.S. Federal publications, averaging $74 \%$. Three documents courses do not include publications-of the States, and 6 omit Municipal publications. All but four of the courses touch upon League of Nations materials, and all but one include the study of United Nations documents. Seven courses out of the I 7 omit consideration of British documents, and only three of the courses reported time spent on any other kinds: county documents, or those of Canada, the major European countries, or South America. Although this breakdown into kinds of documents has little meaning for some courses, such as cataloging, the figures for all schools, and for all courses where this analysis was reported, show about the same distribution: about $75 \%$ of the attention is given to Federal documents, around 10\% of State documents, a little over $6 \%$ to United Nations, about $5 \%$ to Municipal, and $2 \%$ or less each to League of Nations, to British, and to "other" documents. Turning to the Canadian schools it is not surprising to find they average $55 \%$ for Canadian documents, $22 \frac{1}{2} \%$ for British publications, $6 \%$ for League of Nations and United Nations combined, and $16 \frac{1}{2} \%$ for U.S. Federal and State documents. Since only one school in the United States reported spending any time at all with Canadian publications, there seems to be a certain lack of reciprocity here!

The reports of two other topics covered by the questionnaire may be interesting enough to be included here: what do the schools conceive to be their goal in documents instruction, and how satisfied are they with the way the courses are working out? For the first of these questions each school was asked if it was an objective of its government documents instruction that (a) the students should acquire a high level of competence in the actual handling of documents, or if (b) the courses were intended primarily to provide a background of knowledge to which the techniques of handling documents could be added when the student started working with them in a library. These two statements were intended to represent extreme points of view, and the schools were invited to modify them, or to substitute more accurate statements of their actual objectives. Two schools reported that they tried to achieve a 50-50 balance between the two extremes. Two other schools said a high level of competence was an objective of the documents course, but that supplementary courses were intended only to provide background information. Three schools accepted a high level of competence as their goal, while one thought a "fair" degree of competence came nearer to expressing its objective. The other I9 schools that replied to this question accepted the background statement as an objective of their instruction in documents. Of these, one school commented that the background objective was probably "nearer the truth" implying, perhaps, a recognition of the fact that a high level of competence is a desirable but difficult goal. Or as another school expressed it: "The course in government documents attempts to achieve both aims but necessarily, since only one semester is given to government documents material, we must provide the student with a fairly good background of knowledge. It is not possible for a student to achieve a high level of competence by devoting only one course to such a complex subject." 
Now what do the schools and the instructors think about their present programs? It is interesting that the most favorable comment came from an instructor who is approaching the subject from a point of view that if not new, at least was not reported as being common. He writes: "I am particularly enthusiastic regarding the interest of students, especially as we work on problems which deal with the promotion of the use of documents in various types of libraries." The more usual responses ranged from "fairly successful" to "very dissatisfied with course." Three schools that do not now have documents courses plan to introduce them within the next year or two. In another school one instructor states: "there is need for a course concentrated on government publications," while a different instructor in the same school suggests the need for a more careful study of the proper allocation of parts of the subject in existing courses. Two schools with documents courses report dissatisfaction, in one because as the course has been taught in the past, Federal publications tend to swallow up all other kinds, and because there isn't time for enough individual student reports; in the other because the course is so short ( 12 hours) that more than an introductory study of documents is impossible. Perhaps the writer is too optimistic, but the most encouraging thing found in the replies to this questionnaire seemed to be the general air of dissatisfaction that ran through so many of these professorial comments. Complacency is a bad thing in a teacher. But when an instructor thinks a course isn't doing as well as it should, the way is open for changes, and with changes can come improvements.

In summary, the results of this study may serve to reassure those who have been worried about the kind of instruction in public documents the library schools are offering. At .least as far as this sampling is concerned we know now that some instruction about documents is being provided in all of the schools, and that over half of them have documents courses. Even the fact that two patterns of instruction exist need be no cause for alarm, because the same topics seem to be considered with essentially the same degrees of emphasis under both programs. The actual amounts of instruction offered and required vary from school to school, but apparently no student graduates from any school without having had some introduction to public documents. Some librarians may be disheartened that so many schools renounce the objective of training students to a high level of competence in the techniques of handling documents. But this, perhaps, merely reflects a more fundamental problem of library schools, namely, that no curriculum under present conditions can possibly be long enough to teach the students all we think they ought to know about both the theory and the practice of any subject.

\section{Expansion of Farmington Plan}

Under a new type of Farmington Plan coverage, the University of California Library has agreed to accept all publications of research value from the Philippines and Yugoslavia. The volatile political situation in these countries makes total rather than subject field coverage desirable. Arrangements have been made in both countries for the selection and shipment of current books, works issued in series, and sample copies of periodicals. 